\title{
Studies on Mechanical Properties of Kevlar/Napier Grass Fibers Reinforced with Polymer Matrix Hybrid Composite
}

\author{
R. Ganesamoorthy, ${ }^{1}$ R. Meenakshi Reddy $D^{\circ},{ }^{2}$ T. Raja, ${ }^{3}$ Pradeep Kumar Panda $\left(\mathbb{D},{ }^{4}\right.$ \\ Sneha H. Dhoria, ${ }^{5}$ Omaima Nasif, ${ }^{6}$ Saleh Alfarraj, ${ }^{7}$ Velu Manikandan, ${ }^{8}$ and I. Jenish (D) ${ }^{9}$ \\ ${ }^{1}$ Centre for Materials Research, Chennai Institute of Technology, Chennai 600059, Tamil Nadu, India \\ ${ }^{2}$ Department of Mechanical Engineering, G. Pulla Reddy Engineering College, Kurnool 518007, Andhra Pradesh, India \\ ${ }^{3}$ Department of Mechanical Engineering, Vel Tech Rangarajan Dr. Sagunthala R\&D Institute of Science and Technology, \\ 400 Feet Outer Ring Road, Avadi, Chennai 600062, India \\ ${ }^{4}$ Department of Chemical and Materials Engineering, Chang Gung University, Taoyuan 33302, Taiwan \\ ${ }^{5}$ Department of Mechanical Engineering, R.V.R \& J.C College of Engineering, Guntur, Andhra Pradesh, India \\ ${ }^{6}$ Department of Physiology, College of Medicine and King Khalid University Hospital, King Saud University, Medical City, \\ P.O. Box-2925, Riyadh 11461, Saudi Arabia \\ ${ }^{7}$ Zoology Department, College of Science, King Saud University, Riyadh 11451, Saudi Arabia \\ ${ }^{8}$ College of Environmental \& Bioresource Sciences, Jeonbuk National University, Iksan 570752, Republic of Korea \\ ${ }^{9}$ Department of Applied Mechanics, Seenu Atoll School, Hulhumeedhoo, Addu City 19060, Maldives
}

Correspondence should be addressed to I. Jenish; jenish@satollschool.edu.mv

Received 4 August 2021; Accepted 18 September 2021; Published 11 October 2021

Academic Editor: Jinyang Xu

Copyright (c) 2021 R. Ganesamoorthy et al. This is an open access article distributed under the Creative Commons Attribution License, which permits unrestricted use, distribution, and reproduction in any medium, provided the original work is properly cited.

\begin{abstract}
A percentage of natural fibers is used for developing a composite, the materials are quite increasing in recent trends, and they can be a potential replacement of synthetic fibers in the reinforcement phase of hybrid composite. In this research, the combination of natural fibers and synthetic fibers can be used as reinforcement, and epoxy polymer can be used as matrix material. The fibers of Kevlar and Napier grass are reinforced with epoxy matrix to develop a new composite by using conventional hand layup fabrication process and to quantify the effect of this hybrid composite laminate, with five different sequences following. To identify the mechanical properties of this hybrid composite through tensile, flexural, compression strength, impact strength, and hardness tests, among all five samples, sample A was given the maximum mechanical strength, such that the tensile strength is $210 \mathrm{MPa}$, flexural strength is $165 \mathrm{MPa}$, the impact energy absorption is $23 \mathrm{~J}$, the average is $40 \%$ over the other samples, and, at the same time, the compression strength of sample $\mathrm{E}$ is $19 \mathrm{MPa}$, revealing the negative influence of hybrid composite. The SEM morphology was carried out to identify the failure mode of the hybrid composites.
\end{abstract}

\section{Introduction}

The combination of natural fibers and synthetic fibers can give unique properties in physical and chemical categories in a developed composite material [1]. These unique properties are quite increasing the product efficiency and can reduce the environment impact. Composites can be developed either naturally or synthetically. Wood, a characteristic composite, is a mix of cellulose or wood fibers and a substance called lignin [2]. The fiber strengthens wood; lignin is the lattice or normal paste that ties and balances them out. Different composites are engineered (man-made). Compressed wood is a man-made composite that consolidates common and manufactured materials; a composite made of neem and banyan fibers reinforced with epoxy polymer was given a maximum tensile strength of $25 \mathrm{MPa}$; therefore, the utilization of natural fibers with synthetic fibers can improve the mechanical properties of the hybrid composite [3]. Designed 
structures are probably going to be presented to affect loading by outside courses, and this could be relied upon to occur during the maintenance, assembling, and administration tasks. Impact resistance is one of the significant uncertainties in matrix polymer composites [4]. Composites are exceptionally delicate to loading; in this way, after this sort of stacking, they are genuinely harmed, and their mechanical properties are decreased. The term hybrid is defined as combining one or two matrix elements, which resulted as hybrid composites [5]. Hybrid composites are made to join the upside of one fiber with the other. For instance, high modulus fiber like graphite has outstandingly high solidarity to weight proportion, yet their effect quality has commonly been seen as moderately low contrasted and traditional steel and aluminum alloys, and, furthermore, with glass fiber strengthened composites [6]. Henceforth, the utilization of natural fibers alone in the polymer matrix is lacking in sufficiently handling all specialized needs of a fiberstrengthened composite. With an end goal to build up an unrivalled, yet sensible composite, a characteristic fiber can be combined with a manufactured fiber in a similar network material to exploit the properties of both filaments. This results in a characteristic manufactured hybrid fiber composite [7]. The most well-known engineered fiber utilized in these hybrid composites is the glass fiber as a result of ease and simplicity of accessibility contrasting other synthetic strands [8]. The measure of the power required to break material and the sum it reaches out before breaking are significant properties. For most materials, the underlying protection from power or modulus and the purpose of changeless distortion are got from plots of power against elongation [9]. Examination of elongation force or stressstrain curvatures can pass on much about the material being tried, and it can help in anticipating its manner. It is usually estimated in units of force per cross-sectional zone. This is a significant idea in design, particularly in the fields of material science, mechanical structure, and basic design [10]. Hardness test strategies utilize an indenter test that is dislodged from a surface under a particular burden. Space was regularly characterized as stand time. Large scale hardness covers testing with an applied burden more than $1 \mathrm{~kg}$ or around 10 Newtons $(\mathrm{N})$. Microhardness testing with applied loads under $10 \mathrm{~N}$ is commonly utilized for small sample sizes, plated surfaces, or thin films [11]. Microstructure examination is finished by utilizing the optical magnifying instrument; however, these days, there is improvement finished with a computerized investigation utilizing image processing techniques. By utilizing this examination, we can discover that the yield quality and extreme flexible or compressive quality are not also settled predominantly, because of the high hardness and low malleability that make the declaration of solid data of the material a difficult task. Fibers have been delivered utilizing various materials, for example, steel, polypropylene, and glass, among others, slowly across the board in various applications, specifically in the creation of fiber-strengthened cement, [12]. Composites reinforced with plant fibers are especially intriguing, particularly flax fiber strengthened polymers (FFRP). Build up a vacuum packing technique to investigate the mechanical properties of covers arranged on various pieces of banana and E-Glass fabrics. The mechanical properties assessed are elasticity, flexural quality, sway quality, and hardness. Portrayed mechanical property assessment of glass-jute fiber reinforced polymer composites. Glass-jute fiber strengthened polymer composite is created, and the mechanical properties are examined, the reinforcement (60\%) and matrix $(40 \%)$ of the composite laminates are different weight fractions of reinforcement, and the natural fibers utilized to assess the effect of the hybrid composites are chopped bamboo fibers and kenaf fiber in the matrix and type of woven fabric, conducting a dynamic mechanical analysis to determine the storage modulus (DMA) and the results of the chopped bamboo laminates $[13,14]$. The materials chosen for the investigations were jute fiber and glass fiber as the support and epoxy sap as the matrix. The hand layout strategy was utilized to manufacture these composites. Cracked surfaces were exhaustively analyzed using SEM to decide the microscopic crack mode [15]. Results indicated that, by fusing the ideal measure of jute filaments, the general quality of the glass fiber strengthened composites can be expanded, and cost sparing of beyond 30\% can be accomplished. It would, thus, be able to be surmised that jute fiber can be an exceptionally potential up-and-comer in the manufacture of composites, particularly for the incomplete substitution of significantly expense glass fibers for low load bearing capacities [16]. In comparison with other hybrid composite samples, the hardness and water absorption values of the hybrid composite increased with 83 hardness numbers and 1.2 percent water absorption capacity when equal weight fractions of neem and banyan fibers were used. When the applied loading is applied to the hybrid composite, the matrix failure rate and fracture are predominant, as indicated by the micrographs [17]. Portrayed hybrid composites of glass/bamboo fiber were fortified to assess the impact of stacking arrangement on ductile, flexural, and erosive wear properties of mixture polymer composites. The outcomes demonstrated that the properties of bamboo composite can be altogether improved by consolidation of glass fiber in polymer composite. The layer succession has a more prominent impact on the mechanical and tribological properties of the hybrid composite in the developed composite made of neem fiber and banyan fibers are analyzed with dynamic mechanical behavior, and it shows that the solidness of the material with high temperature ratio and the glass transition temperature of $89^{\circ} \mathrm{C}$ can withstand the material with the storage modulus of $1150 \mathrm{MPa}$; therefore, reinforcement of natural fibers can give good dynamic properties, and, at the same time, the addition of synthetic fiber can improve the materials behavior in static and dynamic loading conditions of hybrid composite. [18].

From the above details about the hybrid composite, the research gap was identified; in the present work, the combination of natural and synthetic fibers is Napier grass and Kevlar fibers selected for reinforcement, using epoxy polymer as matrix material to identify the effect of this hybrid composite with varying layers of fiber sequence to conduct the mechanical behavior and analyze the surface morphology of hybrid composite. 


\section{Materials and Methods}

2.1. Materials Used. The hybrid materials are selected on the base of material properties such as mechanical strength and dynamic strength [19]. The common materials are selected over layup with various arrangements. Kevlar is a synthetic fiber, and Napier grass is a natural fiber, which is collected as woven fabric from go Green Pvt. Limited, Chennai, India, and the epoxy resin araldite LY 556 type and hardener HY 951 type were selected as matrix materials, and they were collected from Javanthi enterprises Chennai India. The general properties of reinforcement materials, Kevlar fiber and Napier grass fiber, are given in Table 1 and the epoxy matrix material properties are given in Table 2.

2.2. Experimental Methods. In this work, the reinforcement of Kevlar and Napier grass fibers is selected with epoxy matrix to fabricate the hybrid composite by traditional hand layup technique. Steel mould box $30 \mathrm{~cm} \times 30 \mathrm{~cm}$ is selected for the fabrication process; initially, the steel mould box is cleaned thoroughly, and it keeps the thin layer of polythene sheet and applies the wax to this thin sheet for releasing agent [20]. As per the fiber volume fraction $40 \%$ of reinforcement and $60 \%$ of matrix material is selected. A thin nonreactive laminate is used to cover the steel board to attain a decent superficial finish. After the process, the mould releasing mediator is applied for sticking the polymer resin to the surface [21]. The resin material is functional as layered by a brush, and the Kevlar fiber mat and Napier grass mat were placed accordingly on the steel board. The stacking sequences of these fibers are varied and develop five different laminates of the hybrid composite. The completely wetted fiber laminated composite is then allowed to cure for 4 hours at a temperature of around $75^{\circ} \mathrm{C}$ in a hot air furnace at a very slow rate of heating $\left(10^{\circ} \mathrm{C}\right.$ per minute), followed by 2 hours of postcuring at a temperature of $120^{\circ} \mathrm{C}$ [22]. Schematic image of the hand layup fabrication process is shown in Figure 1 and the production of Kevlar/Napier grass fiber hybrid composite is shown in Figure 2.

2.3. Mechanical Properties of Hybrid Composite. Weight concentration and stacking sequence of $\mathrm{K} / \mathrm{N}$ hybrid composite laminates are given in Table 3 . The most widely recognized and thoroughly utilized testing is tensile testing. Different tests are kept away from for a homogeneous material, and there is an immediate connection between the tensile and compression. The testing samples of Kevlar/ Napier grass fiber hybrid polymer composite are shown in Figure 3.

Tensile Testing: The tensile test is performed as per ASTM 638 standard on the hybrid composite at ambient temperature with a slow rate of loading $(1 \mathrm{~mm} / \mathrm{min})$, and the compressive test is performed as per ASTM 3410 standard on the hybrid composite using the same UTM as the tensile test [23].

Izod Impact Test: As per ASTM D256, the Izod impact test is used to evaluate the impact resistance of hybrid
TABle 1: General properties of Kevlar fiber and Napier grass fiber.

\begin{tabular}{lcc}
\hline Properties & Kevlar fiber & Napier grass fiber \\
Category & Synthetic fiber & Natural fiber \\
Type & Bidirectional woven & Bidirectional woven \\
GSM & fabric & fabric \\
Fiber & 200 & 200 \\
diameter & 50 micron (avg) & 40 micron (avg) \\
Density & $1.44 \mathrm{~g} / \mathrm{cc}$ & $1.25 \mathrm{~g} / \mathrm{cc}$ \\
\hline
\end{tabular}

TABle 2: Properties of epoxy polymer resin.

\begin{tabular}{lc}
\hline \multicolumn{2}{c}{ Matrix material: epoxy polymer resin } \\
\hline Aspect (visual) & Clear liquid \\
Density at $30^{\circ} \mathrm{C}$ & $1.23 \mathrm{~g} / \mathrm{cc}$ \\
Viscosity at $30^{\circ} \mathrm{C}$ & $10-12 \mathrm{~Pa} \mathrm{~s}$ \\
Curing temperature & $75^{\circ} \mathrm{C}$ \\
Glass transition temperature $(\mathrm{Tg})$ & $120^{\circ} \mathrm{C}$ \\
\hline
\end{tabular}

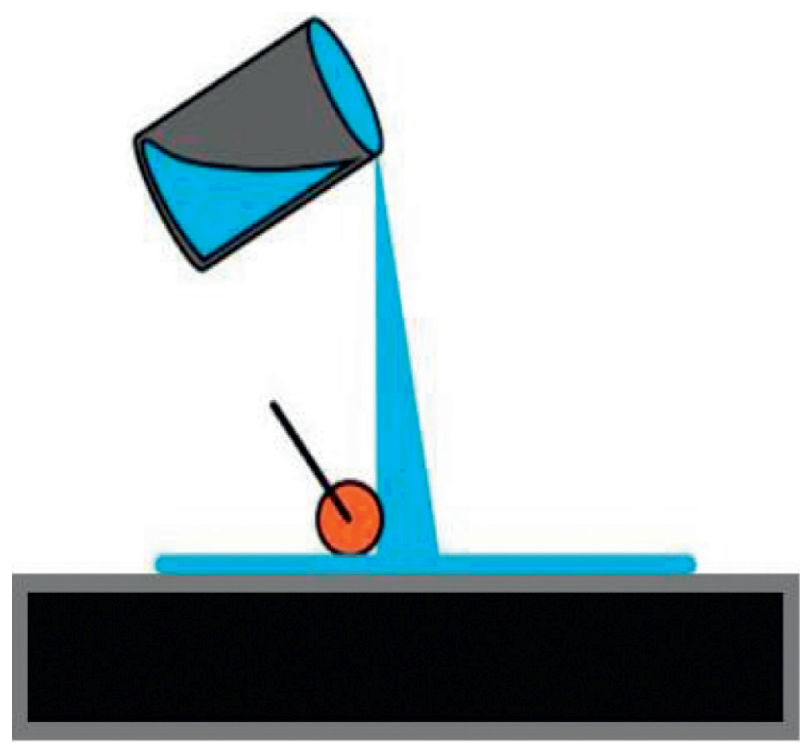

FIGURE 1: Schematic image of hand layup process.

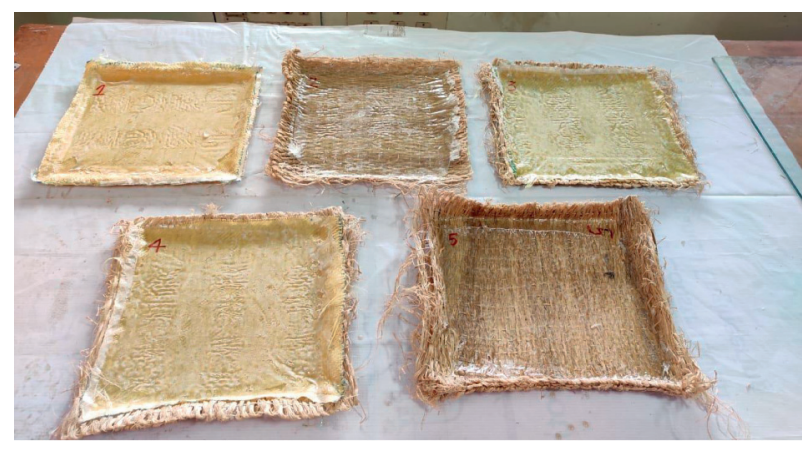

FIgURE 2: Fabrication of K/N fiber hybrid polymer composite.

composites. The impact test is done on hybrid composites to assess the impact energy absorption capacity of the hybrid composite based on the fiber weight fraction and stacking sequences of the constituent fibers [24]. 
TABLE 3: Stacking sequence of hybrid composite laminates

\begin{tabular}{lcccccc}
\hline Sample & $\begin{array}{c}\text { Weight of } \\
\text { Kevlar fiber in g }\end{array}$ & $\begin{array}{c}\text { Weight of Napier } \\
\text { grass fiber in g }\end{array}$ & $\begin{array}{c}\text { Weight fraction of } \\
\text { Kevlar/Napier grass } \\
\text { fiber }\end{array}$ & $\begin{array}{c}\text { Weight of epoxy } \\
\text { matrix in g }\end{array}$ & $\begin{array}{c}\text { Weight of } \\
\text { composite } \\
\text { laminate }\end{array}$ & $\begin{array}{c}\text { Stacking sequence of } \\
\text { Kevlar/Napier grass mat }\end{array}$ \\
\hline A & 150 & 0 & $4: 0$ & 220 & 370 & K-K-K-K \\
B & 112 & 38 & $3: 1$ & 220 & 370 & K-K-K-N \\
C & 75 & 75 & $1: 1$ & 220 & 370 & K-K-N-N \\
D & 38 & 112 & $1: 3$ & 220 & 370 & N-N-N-K \\
E & 0 & 150 & $0: 4$ & 220 & 370 & N-N-N-N \\
\hline
\end{tabular}

K, Kevlar fiber mat, N, Napier grass fiber mat.

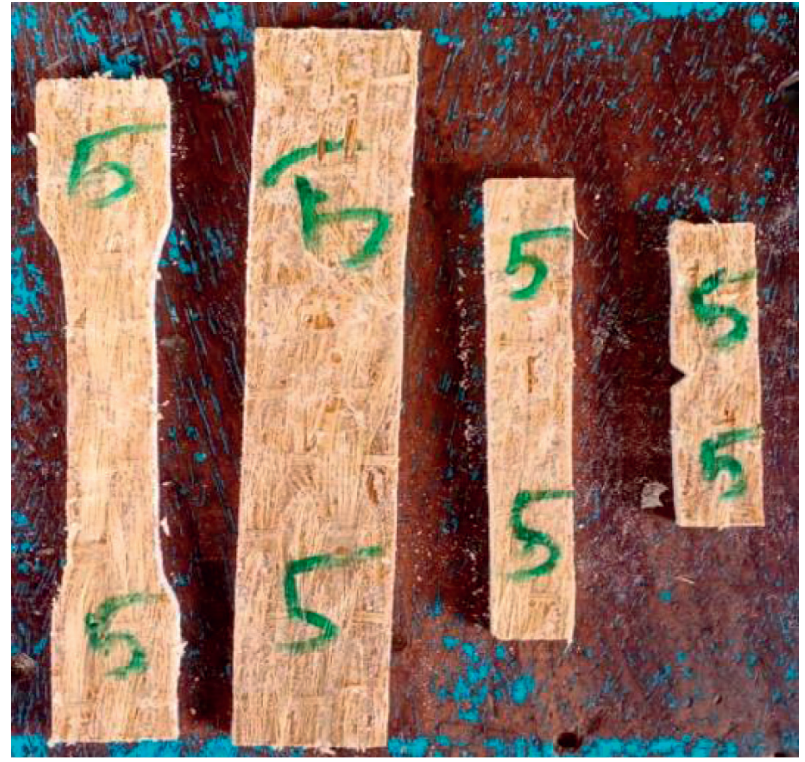

Figure 3: Testing samples of $\mathrm{K} / \mathrm{N}$ hybrid composite.

Flexural Testing: The ASTM Standard D790-03 was used to create the flexural test specimens, which were fabricated from a composite plate. The specimen was $127 \mathrm{~mm} \times 12.7 \mathrm{~mm} \times 5 \mathrm{~mm}$ in dimension. The flexural test was performed at $28^{\circ} \mathrm{C}$ with a relative humidity of $502 \%$ using the Lloyd instrument LR $100 \mathrm{kN}$. The crosshead moved at a rate of $2 \mathrm{~mm} / \mathrm{min}$. The sample was loaded until the core cracked, as shown in Figure 3, 64.1, and the flexural strength and flexural loads were recorded. The values of the flexural modulus were determined [25]. For each composition, three samples were evaluated, and the mean value was reported.

Hardness Testing: The Rockwell hardness test is used to determine the hardness of the hybrid composite in this study. The specimens were prepared in accordance with ASTM E 18-07. The load range for the Rockwell hardness testing equipment is $60 \mathrm{kgf}-150 \mathrm{kgf}$, using a $1 / 16$ inch steel ball indenter. The load value of $60 \mathrm{kgf}$ is used in this study, and the impression is detected in the hybrid composite. The hardness value of the hybrid composite is measured using the dial gauge in the testing equipment based on the impression [26]. The same method is repeated three times for each sample of natural fiber hybrid composite and the average hardness values of hybrid composite, and three trial list samples are taken. Scanning Electron Microscope is used to examine the surface interaction and morphology of the hybrid composite. The hybrid composites are sputter coated with gold particles prior to surface microanalysis to improve visibility.

\section{Results and Discussion}

3.1. Tensile Strength of Epoxy Composite. Tensile strength of epoxy composites with different weight fraction is shown in Figure 4 . The hybrid composite is made of synthetic fibers of Kevlar mat, and natural fibers of Napier grass mat are selected for reinforcement with $40 \%$, and epoxy resin with harden used as matrix is $60 \%$ for the samples. Weight fractions of Kevlar/Napier grass fibers varying in the samples are as follows: 150/0,112/38, 75/75, 38/112, and 0/ 150. Based on this tensile experiment, increasing the weight ratio of Kevlar fiber has given significant values of tensile strength compared to the increasing Napier grass fibers; however, the variations in the results are higher in amount. Therefore, the comparison between synthetic fibers with natural fibers can give unique properties for lower tensile applications. Regarding the output from this tensile analysis, sample A has given higher tensile strength of $210 \mathrm{MPa}$, and this value shows $89 \%$ higher than sample E. Sample E contains a total composite laminate, which is made with the reinforcement of Napier grass fibers. For the comparison between samples B and D, sample B has $69 \%$ higher tensile strength compared with sample D due to the higher weight ratio of Kevlar fibers present in sample B containing $112 \mathrm{~g}$ Kevlar fiber and $38 \mathrm{~g}$ Napier grass fiber. The results can also depend on the stacking sequence of these fibers, the bonding of the Kevlar mat with epoxy matrix is a high covalent bond, and it can resist more during tensile loading, and the stress distribution also is high when increasing with Kevlar fiber mat.

In the above graph, it is revealed that the variation between samples $\mathrm{A}$ to $\mathrm{E}$ is decreasing the tensile strength when the equal weight ratio of $\mathrm{K} / \mathrm{N}$ indicates that the $61 \mathrm{MPa}$ of tensile strength is $71 \%$ lower than sample $\mathrm{A}$ and $51 \%$ lower than sample B. The major reason for the lower tensile strength in sample $\mathrm{E}$ is that all layers contained Napier grass fibers with epoxy matrix and are bonded thoroughly; however, the composite laminates can release the bonding when applying of tensile load, and this indicates that the fiber properties can play an important role during the tensile experiment [27]. Therefore, Kevlar fibers can be suitable for higher tensile applications compared to Napier grass fibers, 


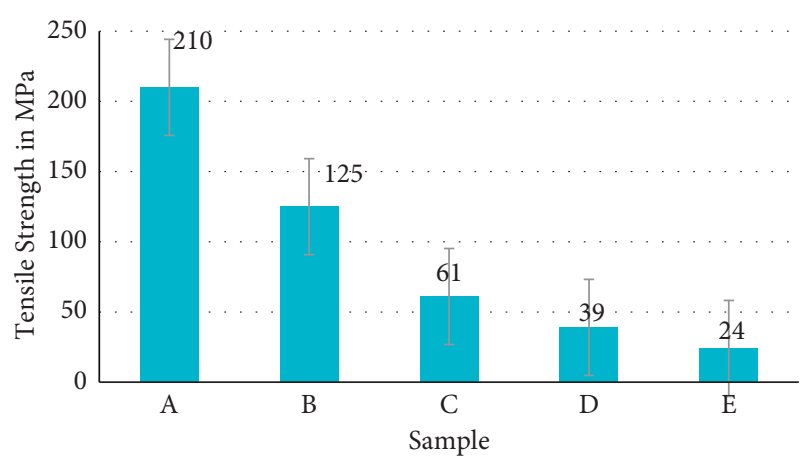

FIgURE 4: Tensile Strength of K/N hybrid composite laminates.

because they withstand higher tensile loading. The failure mode of the hybrid composite can be identified during the morphological analysis.

3.2. Compressive Strength of Hybrid Composite. Similar to tensile strength, the compressive strength of hybrid composite can be identified from five different samples of Kevlar/Napier grass fiber composite laminates. In this result, to quantify the effect of hybrid composite during compression test, the compressive strength of the hybrid composite is shown in Figure 5. The graph revealed that when the increase of Kevlar fiber mat has been given, a positive influence of hybrid composite in sample A shows higher compressive strength of $150 \mathrm{MPa}$, compared to other higher samples, and it contains four layers of Kevlar fiber; in sample B, it shows $81 \mathrm{MPa}$ of compressive strength, and it contains three layers of Kevlar and one layer of Napier grass fiber mat giving $46 \%$ reduced compressive strength compared with sample A.

Adding equal amount of Kevlar/Napier grass fibers can give $42 \mathrm{MPa}$ of compressive strength, and it is $72 \%$ lesser than sample A, and, at the same time, sample D containing equal ratio with different sequences of fibers compared with sample B can give $23 \mathrm{MPa}$. It shows $71 \%$ lesser than sample B. In sample E, all layers of natural fibers of Napier grass fiber show the least value of compressive strength of $19 \mathrm{MPa}$, and it shows $87 \%$ lesser than sample A. Therefore, it can be determined that the decrease of Kevlar fiber mat and the increase of Napier grass fiber mat gave the negative influence of hybrid composite laminates. In another work, the neem and banyan fibers are used to calculate the compressive strength of hybrid composite showing the better result of $23 \mathrm{MPa}$ [28]. The present study reveals that the addition of 3layer Napier grass with one layer of Kevlar fiber mat can compensate for the same results.

\subsection{Flexural Strength of Hybrid Composite Laminates.} Flexural strength of this hybrid composite can be identified from the different stacking sequence effect, and it is the gradual load applied on the direct contact of materials; it was performed under three-point bending test. In this work, the flexural strength was calculated for $2 \mathrm{~mm}$ deflection of the hybrid composite during this experiment.

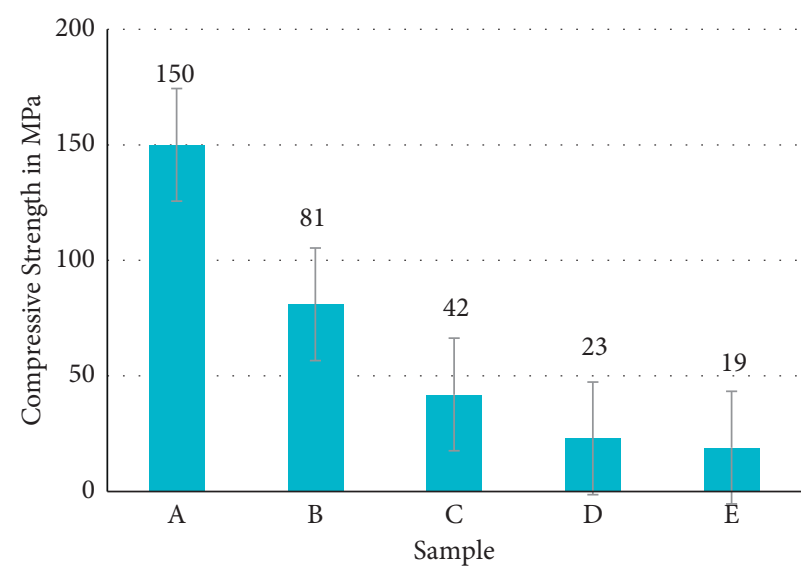

FIGURE 5: Compressive strength of K/N hybrid polymer composite.

The result showed that sample A was given a significant result over other samples, and it shows $42 \%$ more flexural capacity when compared with sample B, and it is contained in three layers of Kevlar and one layer of Napier grass fiber mat with epoxy matrix. It can withstand $70 \%$ more flexural load compared with sample D, in this category, samples B and $\mathrm{D}$ are sample weight fraction with different fibers of $\mathrm{K} /$ $\mathrm{N}$; however, Kevlar fiber mat can improve the flexural load capacity compared with Napier grass fiber mat. The flexural strengths of the hybrid composite of $\mathrm{K} / \mathrm{N}$ laminates are shown in Figure 6.

When applied, the equal amount of natural and synthetic fibers of $\mathrm{K} / \mathrm{N}$ composite laminates has been given $51 \mathrm{MPa}$ flexural strength; this value is $69 \%$ lesser than that of sample A. The impact of adding two layers of Napier grass fiber mat shows a negative influence of hybrid composite compared with four layers of Kevlar fiber composite laminate. In another work, banyan/ramie fibers are used as reinforcement in equal amount, with epoxy matrix polymer composite being developed and giving the good flexural behavior of $35 \mathrm{MPa}$ [29]. This result can be compared with that of the present study, where the equal amount of Kevlar/Napier grass fibers gave $51 \mathrm{MPa}$ flexural strength, and it shows 31\% higher flexural strength, and it can be developed for an alternate material for gradual loading applications of hybrid composite.

3.4. Impact Energy of Hybrid Composite. Impact strength was calculated from the Izod impact test for this hybrid composite, the material can withstand gradual load normally, and it can be an important analysis to check the impact energy absorption for a new material [30]. In this study, two fibers are selected to quantify the effect of impact energy of this hybrid composite, the results are the same like other mechanical properties of the sample, and $\mathrm{A}$ is a higher impact energy of $23 \mathrm{~J}$ and can absorb during the sudden force applied on the $\mathrm{K} / \mathrm{N}$ composite specimen. When the addition of one-layer Napier grass fiber mat was given $19 \mathrm{~J}$, it shows $25 \%$ weight fraction impact of $17 \%$ lesser impact energy compared with all four layers of Kevlar fiber mat; however, it can be an improved result because of $8 \%$ 


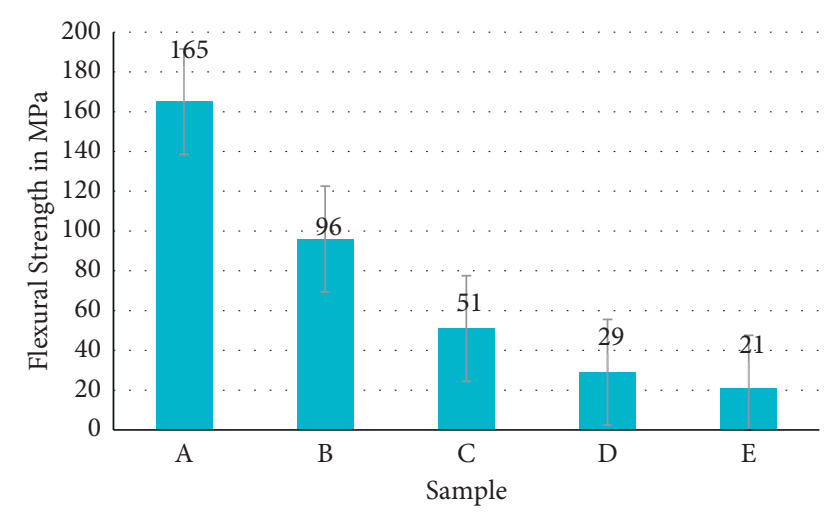

FIGURE 6: Flexural strength of K/N hybrid composite laminates.

deviation in the results of material weight fraction. When adding two layers of Napier grass fiber with two layers of Kevlar fiber was given $13 \mathrm{~J}$ impact energy absorption, it shows $32 \%$ negative influence over sample $B$. The impact energy of $\mathrm{K} / \mathrm{N}$ fiber hybrid composite laminates is shown in Figure 7.

Impact energy results can be compared with other mechanical properties of tensile, flexural, and compressive strength, and it shows good response to gradual deviation between the samples of hybrid composite. Sample D contains 3 layers of Napier grass fibers and one layer of Kevlar fiber, and the mat was given $12 \mathrm{~J}$, and this can be compared with the same sequence with more Kevlar weight fraction in sample B that is $37 \%$ more impact energy and in sample E also $57 \%$ lesser impact energy compared with sample A. It can be calculated when increasing Napier grass and decreasing Kevlar fiber weight fraction show the negative influence of hybrid composite laminates.

3.5. Hardness Value of Hybrid Composite Laminates. Hardness values of hybrid composite laminates are calculated from Rockwell hardness experiment; in this study, to quantify the hardness capacity of Kevlar and Napier grass fibers, the composite was identified, and the results are shown in Figure 8. Among the five different samples, sample A was given higher hardness number of the hybrid composite. The output of this experiment is majorly depending upon the top layer of the hybrid composite material and in samples A, B, and C having Kevlar fiber mat, the top layer of composite laminates can reflect the results of hardness values. In sample B, we got 86 of $\mathrm{RHN}$, and it is $8 \%$ lesser than sample A, so the hardness values are depending on not only the top layer, but also the impact of the top layer that is more on the hardness value output of this hybrid composite. When the equal amounts of both fibers of Kevlar and Napier grass fibers are the same, $8 \%$ lesser than sample B, however, sample B of three layers of synthetic fiber and one layer of natural fiber.

In another work, a developed composite with jute fiber was given, $87 \mathrm{RHN}$ with the addition of fillers can impact on this material [31], and, at the same time, this work reveals

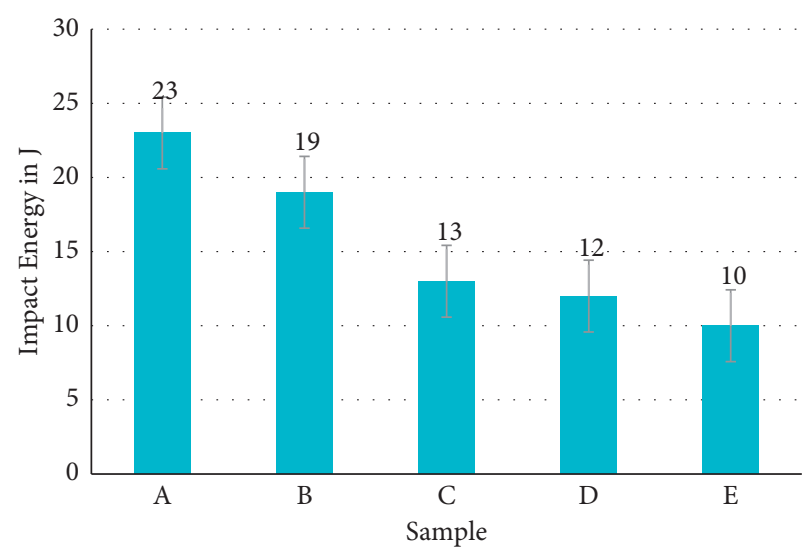

FIGURE 7: Impact energy of K/N fiber hybrid composite.

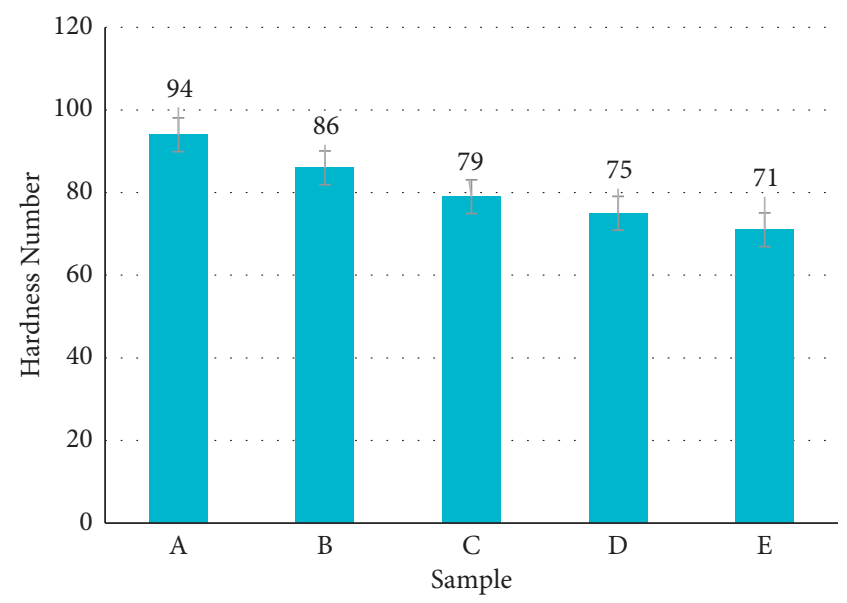

Figure 8: Hardness number of K/N hybrid polymer composite.

that, without any filler, the materials can reach higher values. The deviations between the samples are also less with other properties, sample D has $12 \%$ lesser RHN compared with sample $\mathrm{B}$ with the same sequence and different weight fractions, and the top layer of Napier grass can resist the gradual loading in hardness capacity. Sample E shows the least value of 71 RHN compared to sample A, 24\% lesser hardness value of hybrid composite laminates.

3.6. Morphological Analysis. The conclusion from the Scanning Electron Microscopy (SEM) micrographs is obvious from the pictures that the fiber pull-outs, cracks, and failure are the major causes of hybrid fiber failure when subjected to tensile loading [32]. These failures are usually produced owing to the weak contact between the matrix orientations, which leads to the stress concentration producing catastrophic failure in the hybrid composite. Because of the increased level of stress concentration in the material, increasing the weight fraction of Napier grass fiber in hybrid composites results in a more complex level of cracks. The SEM micrographs of the hybrid composite are shown in Figure 9. 

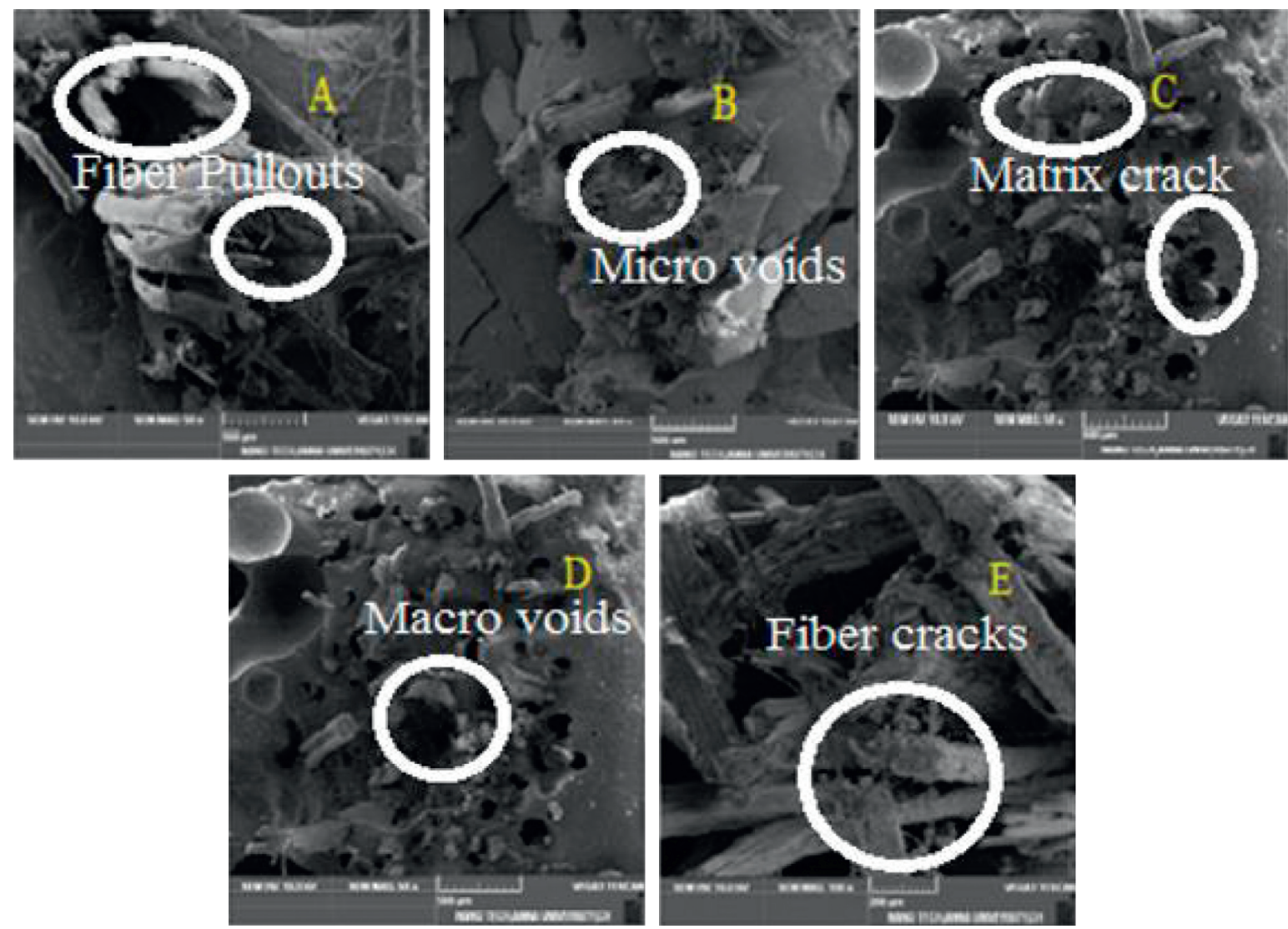

FIgURE 9: SEM micrographs of K/N hybrid composites.

\section{Conclusion}

Towards the improvement of natural fibers with synthetic fiber reinforcement, we can give the unique properties of hybrid composite for light weight applications. The followings are the main findings from the above works:

(i) The utilization of Kevlar fiber weight fraction in the sample A gave higher tensile strength of $210 \mathrm{Mpa}$, compressive strength of $150 \mathrm{MPa}$, flexural strength of $165 \mathrm{MPa}$, and impact energy of $23 \mathrm{~J}$. The average of $40 \%$ improved the mechanical properties in sample A and $89 \%$ higher than sample $E$ of the hybrid composite.

(ii) In sample B, three layers of Kevlar fiber mat and one layer of Napier grass fiber mat gave significant results over sample D in different weight fractions. Equal numbers of fibers also can give significant results for light weight applications.

(iii) Therefore, synthetic fiber layers can give the positive influence of these mechanical properties of the hybrid composite. Natural fiber layers increased the failure rate compared to synthetic fiber composite.

(iv) Surface morphology reveals the failure rate and failure mode of hybrid composites, and the increase of Napier grass fiber composite laminates occurred with more stress concentration leading to material failure during the gradual loading. (v) It can be determined that the amount of Napier grass fibers can utilize the light weight application with the addition of synthetic fibers, can improve the results, and can be used in aerospace applications of hybrid composite.

\section{Data Availability}

The data used to support the findings of this study are included within the article.

\section{Disclosure}

This study was performed as a part of employment in Seenu Atoll School, Maldives.

\section{Conflicts of Interest}

The authors declare that there are no conflicts of interest regarding the publication of this article.

\section{Acknowledgments}

The authors appreciate the supports from Seenu Atoll School, Maldives. The authors thank Chennai Institute of Technology, Chennai, and Vel Tech Rangarajan Dr. Sagunthala R\&D Institute of Science and Technology, Chennai, for providing technical assistance to complete this experimental work. This project was supported by researchers supporting project 
number RSP-2021/257, King Saud University, Riyadh, Saudi Arabia.

\section{References}

[1] T. G. Yashas Gowda, M. R. Sanjay, K. Subrahmanya Bhat, P. Madhu, P. Senthamaraikannan, and B. Yogesha, "Duc Pham Polymer matrix-natural fiber composites: an overview," Cogent Engineering, vol. 5, no. 1, Article ID 1446667, 2018.

[2] K. Yorseng, M. R. Sanjay, J. Tengsuthiwat et al., "Information in United States patents on works related to 'natural fibers': 2000-2018," Current Materials Science, vol. 12, no. 1, pp. 4-76, 2019.

[3] R. Thandavamoorthy and A. Palanivel, "Testing and evaluation of tensile and impact strength of neem/banyan fiberreinforced hybrid composite," Journal of Testing and Evaluation, vol. 48, no. 1, pp. 647-655, 2020.

[4] S. Mr, S. Siengchin, J. Parameswaranpillai, M. Jawaid, C. Pruncu, and A. Khan, "A comprehensive review of techniques for natural fibers as reinforcement in composites: preparation, processing and characterization," Carbohydrate Polymers, vol. 83, no. 11, pp. 108-121, 2018.

[5] K. Bharath, M. Sanjay, M. Jawaid, S. Basavarajappa, and S. Siengchin, "Effect of stacking sequence on properties of coconut leaf sheath/jute/E-glass reinforced phenol formaldehyde hybrid composites," Journal of Industrial Textiles, vol. 49, no. 1, pp. 3-32, 2019.

[6] S. Abhishek, M. R. Sanjay, G. Raji, S. Suchart, J. Parameswaranpillai, and C. I. Pruncu, "Jyotishkumar Parameswaranpillai \& Catalin Iulian Pruncu Development of new hybrid Phoenix, pusilla/carbon/fish bone filler reinforced polymer composites," Journal of the Chinese Advanced Materials Society, vol. 6, no. 5, pp. 553-560, 2018.

[7] K. Ganesan, C. Kailasanathan, M. R. Sanjay, P. Senthamaraikannan, and S. S. Saravanakumar, "A new assessment on mechanical properties of jute fiber mat with egg shell powder/nanoclay-reinforced polyester matrix composites," Journal of Natural Fibers, vol. 17, no. 4, pp. $480-490,2018$.

[8] P. Kumaran, S. Mohanamurugan, S. Madhu et al., "Investigation on thermo-mechanical characteristics of treated/untreated Portunus sanguinolentus shell powder-based jute fabrics reinforced epoxy composites," Journal of Industrial Textiles, vol. 50, no. 4, pp. 427-459, 2019.

[9] P. Madhu, M. R. Sanjay, P. Senthamaraikannan, S. Pradeep, S. S. Saravanakumar, and B. Yogesha, "A review on synthesis and characterization of commercially available natural fibers: Part-I," Journal of Natural Fibers, vol. 16, no. 8, pp. 1132-1144, 2018.

[10] T. Raja and P. Anand, "Evaluation of thermal stability and thermal properties of neem/banyan reinforced hybrid polymer composite," Materials Performance and Characterisation, vol. 8, no. 1, pp. 481-490, 2019.

[11] K. Mehar, S. K. Panda, and T. R. Mahapatra, "Thermoelastic deflection responses of CNT reinforced sandwich shell structure using finite element method," Scientia Iranica, vol. 25, pp. 2722-2737, 2017.

[12] S. D. Salman, Z. Leman, M. T. H. Sultan, M. R. Ishak, and F. Cardona, "The effects of orientation on the mechanical and morphological properties of woven kenaf-reinforced poly vinyl butyral film," Bio Resources, vol. 11, no. 1, pp. 1176-1188, 2015.

[13] T. Raja, P. Anand, K. Karthik, and J. Udaya Prakash, "Mechanical properties and moisture behaviour of neem/banyan fibres reinforced with polymer matrix hybrid composite," Advances in Materials and Processing Technologies, pp. 1-12, 2021.

[14] M. Jawaid, H. P. S. Abdul Khalil, and O. S. Alattas, "Woven hybrid bio-composites: dynamic mechanical and thermal properties," Composer Part A Appl Sci Manuf, vol. 43, no. 2, pp. 288-293, 2011.

[15] V. J. Binu Kumar, J. Bensam Raj, R. Karuppasamy, and R. Thanigaivelan, "Influence of chemical treatment and moisture absorption on tensile behavior of neem/banana fibers reinforced hybrid composites: an experimental investigation," Journal of Natural Fibers, pp. 1-12, Article ID 1838995, 2020.

[16] R. Balaji, M. Sasikumar, and A. Elayaperumal, "Thermal, Thermo oxidative and Ablative behavior of cenosphere filled ceramic/phenolic composites," Polymer Degradation and Stability, vol. 114, pp. 125-132, 2015.

[17] E. Chandana and I. Syed Altaf Hussian, "Thermal conductivity characterization of bamboo fiber reinforced in epoxy resin," IOSR Journal of Mechanical and Civil Engineering, vol. 9, no. 6, pp. 7-14, 2013.

[18] T. Raja and P. Anand, "Investigations on dynamic mechanical analysis and crystalline effect of neem/banyan fiber-reinforced hybrid polymer composite," Journal of Testing and Evaluation, vol. 50, no. 1, Article ID 20200580, 2022.

[19] P. G. García, R. Ramírez-Aguilar, M. Torres, E. A. FrancoUrquiza, J. May-Crespo, and N. Camacho, "Mechanical and thermal behavior dependence on graphite and oxidized graphite content in polyester composites," Polymer, vol. 153, no. 6, pp. 9-16, 2018.

[20] V. Mohanavel, S. Suresh Kumar, J. Vairamuthu, P. Ganeshan, and B. NagarajaGanesh, "Influence of stacking sequence and fiber content on the mechanical properties of natural and synthetic fibers reinforced penta-layered hybrid composites," Journal of Natural Fibers, pp. 1-13, 2021.

[21] H. Alamri, I. M. Low, and Z. Alothman, "Mechanical, thermal and microstructural characteristics of cellulose fibre reinforced epoxy/organoclay nanocomposites," Composites Part B: Engineering, vol. 43, no. 7, pp. 2762-2771, 2012.

[22] U. Achutha Kini, M. Shettar, S. Sharma et al., "Effect of hydrothermal aging on the mechanical properties of nanoclay-glass fiber-epoxy composite and optimization," Using Full Factorial Design Materials Research Express, vol. 6, pp. 510-523, 2019.

[23] M. Atagur, A. Orhan, K. Sever et al., "Investigation of thermal and mechanical properties of synthetic graphite and recycled carbon fiber filled polypropylene composites Materials," Research Express, vol. 6, pp. 524-536, 2019.

[24] T. Raja and P. Anand, "Mechanical investigations on Neem/ Banyan fibers reinforced with ceramic powder particulates hybrid polymer composite helmet," IOP Conference Series: Materials Science and Engineering, vol. 988, Article ID 012090, 2020.

[25] B. Ravichandran and M. Sasikumar, "Mechanical, ablative, and thermal properties of cenosphere-filled ceramic/phenolic composites," Polymer Composites, vol. 37, no. 6, pp. 1906-1913, 2016.

[26] A. Vasudevan, B. Navin kumar, M. V. Depoures, T. Maridurai, and V. Mohanavel, "Tensile and flexural behaviour of glass fibre reinforced plastic -Aluminium hybrid laminate manufactured by vacuum resin transfer moulding technique (VARTM)," Materials Today Proceedings, vol. 33, no. 7, pp. 3072-3079, 2020. 
[27] M. Ramesh, K. Palanikumar, and K. H. Reddy, "Plant fibre based bio-composites: sustainable and renewable green materials," Renewable and Sustainable Energy Reviews, vol. 79, no. 5, pp. 558-584, 2017.

[28] D. Hristozov, L. Wroblewski, and P. Sadeghian, "Long-term tensile properties of natural fibre-reinforced polymer composites: comparison of flax and glass fibres," Composites Part B: Engineering, vol. 95, pp. 82-95, 2016.

[29] A. V. Kiruthika, "A review on physico-mechanical properties of bast fibre reinforced polymer composites," Journal of Building Engineering, vol. 9, pp. 91-99, 2017.

[30] L. Yan, N. Chouw, L. Huang, and B. Kasal, "Effect of alkali treatment on microstructure and mechanical properties of coir fibres, coir fibre reinforced-polymer composites and reinforced-cementitious composites," Construction and Building Materials, vol. 112, no. 1, pp. 168-182, 2016.

[31] A. Q. Dayo, B.-C. Gao, J. Wang et al., "Natural hemp fiber reinforced polybenzoxazine composites: curing behavior, mechanical and thermal properties," Composites Science and Technology, vol. 144, no. 3, pp. 114-124, 2017.

[32] M. Ramesh, C. Deepa, and U. S. Aswin, "Effect of alkalization on mechanical and moisture absorption properties of Azadirachta indica (neem tree) fiber reinforced green composites," Transactions of the Indian Institute of Metals, vol. 70, no. 6, pp. Pp187-199, 2017. 